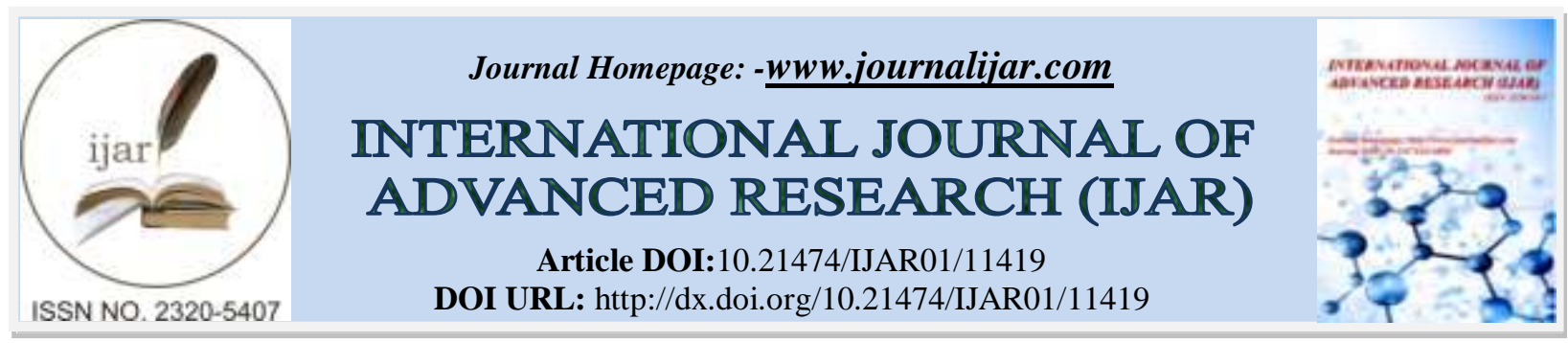

RESEARCH ARTICLE

\title{
CASE REPORT OF SECONDARY SYNOVIAL OSTEOCHONDROMATOSIS WITH TWO GIANT LOOSE BODIESAT THE SUBCORACOID SPACE IN LEFT SHOULDER JOINT OF43-YEAR-OLD FEMALE PATIENT
}

Mahmood A. Qoqandi, Emad A. Elansary, Ahmad A. Alsubahi and Mamdouh E. Almasri MBBS, Medical Resident at Saudi Board of Orthopedic Surgery, Makkah, Saudi Arabia.

\section{Manuscript Info}

a.......................

Manuscript History

Received: 28 May 2020

Final Accepted: 30 June 2020

Published: July 2020

\section{Abstract}

Synovial Osteochondromatosis is a rare and benign condition of unknown cause. Although large joints such as the knee are commonly affected, involvement of the shoulder joint is not common. Synovial Osteochondromatosis may occur secondary to preexisting joint disorders. This article reviews detailed history, examination and investigations of 43 years-old female patient known case of rheumatoid arthritis, diagnosed with loose bodies in her shoulder joint. The present report aimed to highlight the occasional involvement of sub- coracoid space of the shoulder as site of loose bodiesand indicated arthroscopy for retrieval of the loose bodieswith favorable outcome.

Ethical consideration: The patient was informed that data from the case would be submitted for publication, and she gave her consent.

Conflicts of interest: none.

Copy Right, IJAR, 2020,. All rights reserved.

\section{Introduction:-}

Synovial Osteochondromatosis is rare and non-malignant tumor that arises in the lining of a joint (synovium). (1) Originally, it forms when the affected synovium grows abnormally and produces small clumps or nodules of cartilage. These nodules can separate and become loose within the joint,some of it may be no larger than a grain of rice and some of it reach up to being as large as a coin. ${ }^{(2)}$ The most common joint involved is knee joint, followed by the hip, elbow, shoulder. ${ }^{(3,4)}$

The exact prevalence of synovial Osteochondromatosis is unknown, but the disorder is rare worldwide. ${ }^{(1)}$ Most cases reported in patients aged 20 to 50 years with male-to-female ratio of $2: 1{ }^{(1,2)}$ Researchers indicated that Synovial Osteochondromatosis is not inherited condition. (2) The exact underlying cause of synovial Osteochondromatosis is unknown. Some research suggests that Synovial Osteochondromatosis may occurs as either as primary (which is rare) or secondary form. Secondary synovial Osteochondromatosis is the common form and often occurs when there is pre-pathological conditions like rhumatologicaldiseases or infectious diseases. ${ }^{(5)}$ Moreover, trauma may play a role in its development because the condition primarily occurs in weight-bearing joints. $^{(3)}$

Clinically, the Signs and symptoms may include joint pain, swelling, a decreased range of motion, and locking of the joint. ${ }^{(6)}$ Presence of Small bodies lead to locking episodes, whereas larger bodies cause erosion of the cartilage, leading to early onset of arthritis. ${ }^{(2,7)}$ The amount of loose bodies and their size as compared to the relatively small joint space can lead to them occupying the entire joint.Treatment of may be symptomatic, but if mechanical symptoms are prominent, arthroscopic or open removal of the bodies or synovium is warranted. ${ }^{(8)}$ 
In Saudi Arabia, there are low number of synovial Ostoechondromatosis cases in shoulder joints. ${ }^{(9,10)}$ This is the case report with detailed history, examination of 43 years-old female patient with loose bodies in her shoulder joint. The present report aimed to highlight on occasional involvement of sub-coracoid space of the shoulder as site of loose bodies and challenged arthroscopic surgical techniques that utilized as a surgical management approach for this case.

\section{Report of the case: \\ Clinical presentation and history:}

43 years old female known case of Rheumatoid Arthritis on medications, presented to the orthopedic clinic with a two-year history of progressive left shoulder pain. Her symptom was bad enough to disturb her daily activities and usually she needs help in wearing and donning her clothes. There is no history of trauma and during this time, she did not get any improvements with conservative treatment including medication and physiotherapy.

\section{Examination:}

On examination, there was generalized tenderness over the shoulder and affected range of movement; her range of movement was restricted when compared to the other side. Flexion was up to100 degrees, and external rotation was limited to 50 degrees. Internal rotation was up to the point where the patient's hand touched her back at the level of the iliac crest. Clinical examination of the rotator cuff did not reveal any abnormalities and the rotator cuff power was normal.

\section{Investigations and Procedure:}

Initial X ray radiographs revealed that there were findings of glenohumeral arthritis at the left shoulder with no presence of loose bodies (Fig. 1).CT scan and Magnetic resonance imaging (MRI) also showed sever arthritic changes with destruction of the left humeral head. However, the CT scan and MRI (Fig.2 and Fig. 3) performed for assessing bone stock of glenoid and overall assessment of articular joint and rotator cuff integrity. The advanced radiological imaging showed two giant loose bodies in the sub-coracoid space that had not been seen in plain $\mathrm{X}$ rays.

Options were discussed with the patient and she was keen to get her shoulder symptoms improved, as she had failed all non-operative treatment. And due to her age, she was not a candidate for arthroplasty. therefore, A left shoulder arthroscopy was performed, with the patient under general anesthesia, and in beach chair position. Arthroscopic left shoulder debridement along with anterior and posterior capsular release with sub acromial decompression and acromioplasty were performed to relieve patient's symptoms and improve the range of movement. Moreover, biceps tenotomy of inflamed and degenerated long head of biceps was performed. Two large loose bodies at the subcoracoid space had been removed (Fig. 4) through extendedstandard lateral arthroscopy portal.

\section{Postoperative Management and Follow-up:}

Following the surgery, the patient had a good initial improvement without post-operative complications, with a physical therapy plan aiming for improving range of motion. The patient then developed paresthesia and numbness over left side of the body and she was referred to a neurologist for further investigations that came up of no relation with our procedure. The patient was informed that data from the case would be submitted for publication.

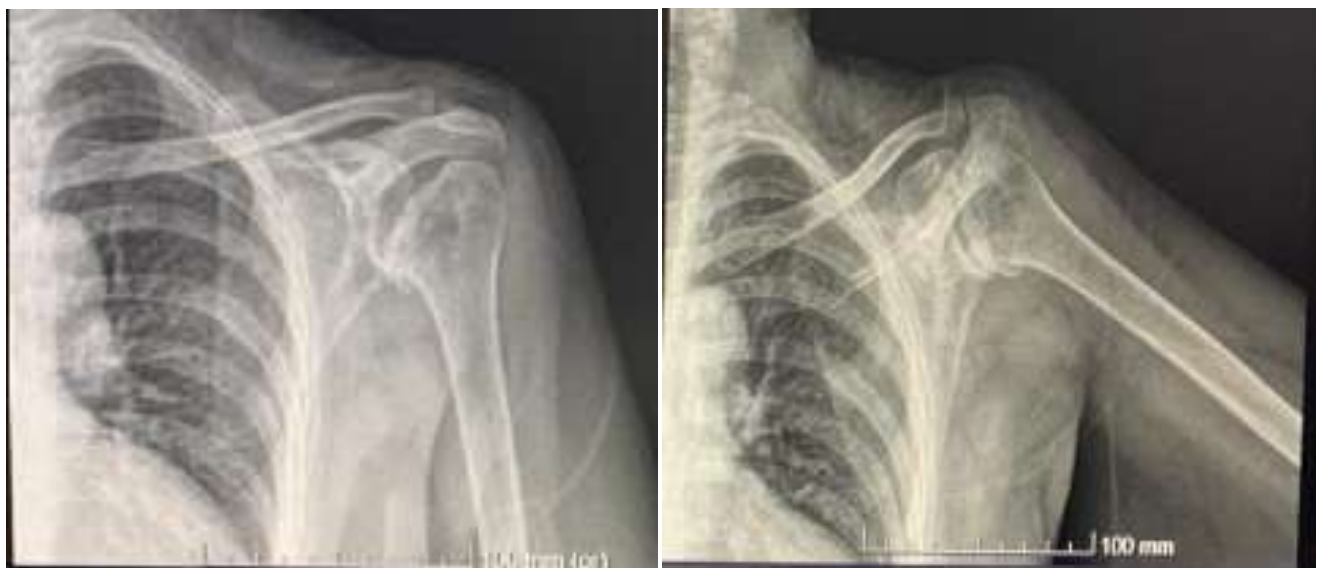

Figure 1:- X-ray radiographs of left shoulder showing glenohumeral arthriti. 

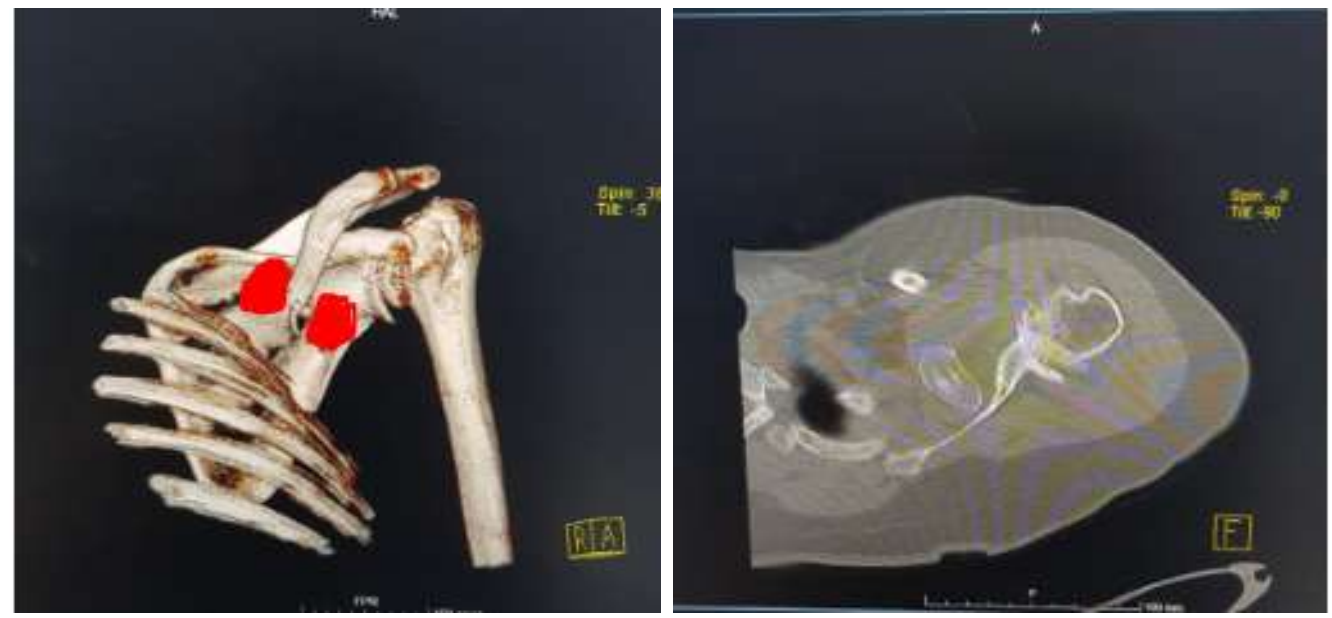

Figure 2:- CT scan (3D left, axial right) showed two loose bodies in sub coracoid space of left shoulder with obvious glenohumeral arthritis.
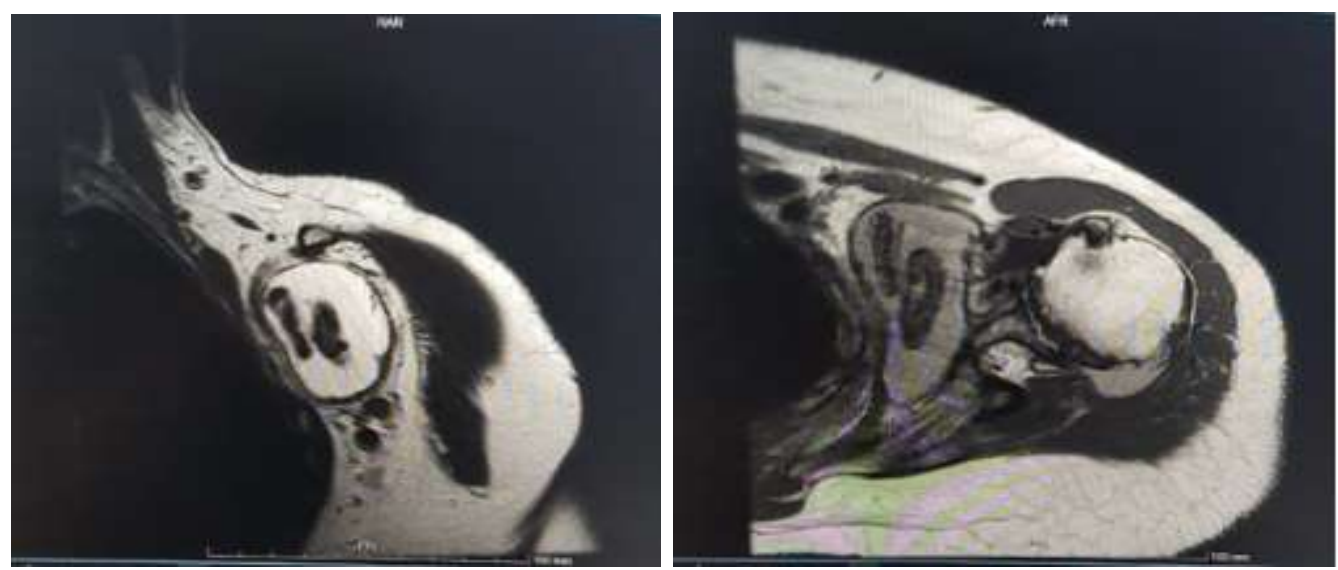

Figure 3:- MRI images of the left shoulder joint with two loose bodies in the sub-coracoid space.

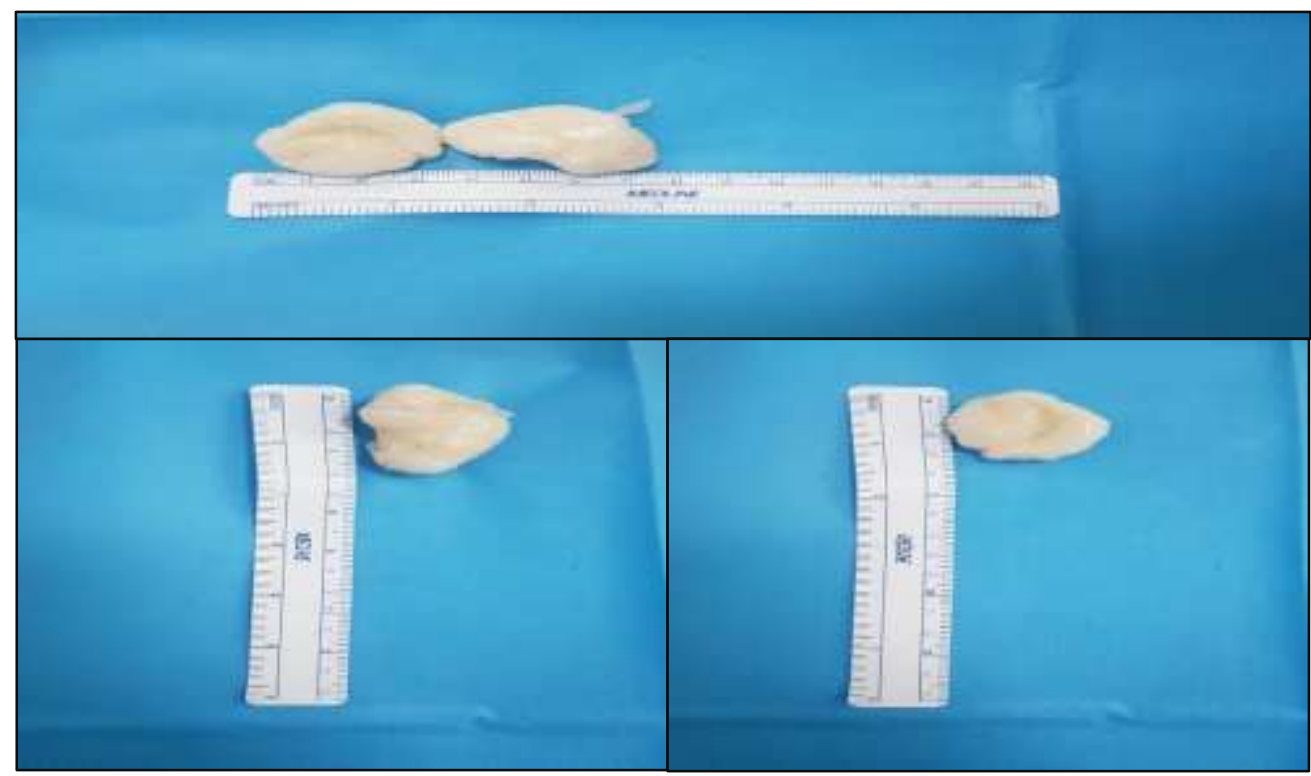

Figure 4:- Two loose bodies of varying sizes after retrieval from the sub-coracoid space of left shoulder joint. 


\section{Discussion:-}

Synovial Osteochondromatosis is an uncommon condition characterized by the formation of multiple cartilaginous nodules within the synovium;after rigorous literature review, it was cleared that our understanding of this condition primarily is based on case reports and small case series studies.

Synovial Osteochondromatosis most commonly affecting large joints such as the knee and hip, involvement of the shoulder joint is a rare entity. ${ }^{(3)}$ Moreover, it has a higher prevalence in the male sex and occurs between the third and the fifth decade. ${ }^{(1,2)}$ The present case is female in the 40 s of her age with pre-existing chronic health condition of rheumatoid arthritis and she had loose bodies in subscapular bursa where the communication with the joint cavity between the superior and middle glenohumeral ligaments. Presence of loose bodies is a contributing factor along with mainlyher gleno-humeral arthritis as the reasons behind the chronic progressive joint pain and movement restriction.

The loose bodies' characteristic of this condition are easily confirmed on plain radiographs and CT if they are calcified or ossified, ${ }^{(11,12)}$ while MRI is useful in the identification of non-calcified and no ossified foci. ${ }^{(13,14)}$ In the present case, the CT and MRI radiological imaging showed two giant loose bodies in the sub coracoid space that not had been seen in plain $\mathrm{X}$ rays.

In context of treatment, the classical treatment for synovial Osteochondromatosis is open arthrotomy, synovectomy and complete removal of the free fragments. ${ }^{(1,2)}$ For retrieval of loose bodies, there has been considerable debate over whether an arthroscopic procedure is better than an open procedure. ${ }^{(15)}$ However, there is no clear evidence that an open procedure, with or without synovectomy, offers any advantage.On the other side,the advantages of arthroscopic treatment include good visualization, low morbidity, rapid healing and early rehabilitation. (16) Indications for arthroscopic treatment have been extended with recent advances in methods of arthroscopic techniques. ${ }^{(17)}$ Furthermore, removal of loose bodies with partial synovectomy and joint reconstruction of the involved joints results in decreased pain, improved mechanical function, and decreased swelling in most cases. Rare re-occurrence is reported following surgical management with partial synovectomy. ${ }^{(18,19)}$ The present patient underwent to arthroscopic left shoulder debridement, capsular release,biceps tenotomy, sub acromial decompression,acromioplasty and removal of loose bodies, future wise she is indicated for arthroplasty. her clinical condition and her age were considered for total shoulder arthroplasty over reverse total shoulder arthroplasty.

\section{Conclusion:-}

Synovial Osteochondromatosis is health condition that can present with joint pain and movement limitation and is best managed by an orthopedic surgeon. Presence concomitant with joint arthritis is possible and can aggravate symptoms. Plain radiographs alone for diagnosis might not be enough and further imaging modalities would be advised. (i.e. MRI for assessment of non-ossifying loose bodies) Advantages of arthroscopic surgical technique islesser morbidity, early rehabilitation, and faster recovery compared to open surgery. However, occasionally in certain conditionsopen procedures may be necessary.

\section{References:-}

1. Synovial

chondromatosis. Children's

Hospital

Boston. http://www.childrenshospital.org/az/Site1034/mainpageS1034P1.html. Accessed 10/7/2019.

2. Joint tumors. Merck http://www.merckmanuals.com/home/sec05/ch063/ch063c.html?qt=synovial\%20chondromatosis\&alt=sh. Accessed 10/7/2019.

3. Crotty JM, Monu JU, Pope Jr TL. Synovial osteochondromatosis. Radiologic Clinics of North America. 1996 Mar 1;34(2):327-42.

4. Buess E, Friedrich B. Synovial chondromatosis of the glenohumeral joint: a rare condition. Archives of orthopaedic and trauma surgery. 2001 Jan 1;121(1-2):109-11.

5. Synovial Chondromatosis. American Academy of Orthopaedic Surgeons. May 2011; http://orthoinfo.aaos.org/topic.cfm?topic=A00602. Accessed 10/11/2019.

6. Chillemi C, Marinelli M, de Cupis V. Primary synovial chondromatosis of the shoulder: clinical, arthroscopic and histopathological aspects. Knee Surgery, Sports Traumatology, Arthroscopy. 2005 Sep 1;13(6):483-8. 
7. Tokis AV, Andrikoula SI, Chouliaras VT, Vasiliadis HS, Georgoulis AD. Diagnosis and arthroscopic treatment of primary synovial chondromatosis of the shoulder. Arthroscopy: The Journal of Arthroscopic \& Related Surgery. 2007 Sep 1;23(9):1023-e1.

8. Bruggeman NB, Sperling JW, Shives TC. Arthroscopic technique for treatment of synovial chondromatosis of the glenohumeral joint. Arthroscopy: The Journal of Arthroscopic \& Related Surgery. 2005 May 1;21(5):633e1.

9. Al-Mendalawi MD. Synovial chondromatosis of the knee joint in infant: A case report and literature review. Saudi Journal of Sports Medicine. 2016 Jan 1;16(1):89-.

10. Algazwi DA, Gartner LE, Manohara R, Hallinan JT. Synovial Chondromatosis of the Shoulder Causing Nerve Compression. JCR: Journal of Clinical Rheumatology. 2020 May 9.

11. Am Jung K, Kim SJ, Jeong JH. Arthroscopic treatment of synovial chondromatosis that possibly developed after open capsular shift for shoulder instability. Knee Surgery, Sports Traumatology, Arthroscopy. 2007 Dec 1;15(12):1499-503.

12. Lunn JV, Castellanos-Rosas J, Walch G. Arthroscopic synovectomy, removal of loose bodies and selective biceps tenodesis for synovial chondromatosis of the shoulder. The Journal of bone and joint surgery. British volume. 2007 Oct;89(10):1329-35.

13. Covall DJ, Fowble CD. Arthroscopic treatment of synovial chondromatosis of the shoulder and biceps tendon sheath. Arthroscopy: The Journal of Arthroscopic \& Related Surgery. 1993 Oct 1;9(5):602-4.

14. Cellerini M, Grasso A, Fidecicchi F, Spaccapeli D. Diagnostic imaging of idiopathic synovial osteochondromatosis. La Radiologia medica. 1995 Jun;89(6):761.

15. Ranalletta M, Bongiovanni S, Calvo JM, Gallucci G, Maignon G. Arthroscopic treatment of synovial chondromatosis of the shoulder: report of three patients. Journal of shoulder and elbow surgery. 2009 May $1 ; 18(3):$ :e4-8.

16. Zhu W, Wang W, Mao X, Chen Y. Arthroscopic management of elbow synovial chondromatosis. Medicine. 2018 Oct; $97(40)$.

17. Raval P, Vijayan A, Jariwala A. Arthroscopic retrieval of over 100 loose bodies in shoulder synovial chondromatosis: A case report and review of literature. Orthopaedic surgery. 2016 Nov;8(4):511-5.

18. Jeon IH, Ihn JC, Kyung HS. Recurrence of synovial chondromatosis of the glenohumeral joint after arthroscopic treatment. Arthroscopy: The Journal of Arthroscopic \& Related Surgery. 2004 May 1;20(5):524-7.

19. Chillemi C, Marinelli M, de Cupis V. Primary synovial chondromatosis of the shoulder: clinical, arthroscopic and histopathological aspects. Knee Surgery, Sports Traumatology, Arthroscopy. 2005 Sep 1;13(6):483-8. 